\title{
ThE NEW ZEALAND INSURANCE AND SAVINGS OMBUDSMAN SCHEME
}

\author{
Stephen Rogers*
}

The New Zealand insurance industry has recently embarked on a programme of selfregulation. At the centre of this programme is the Insurance and Savings Ombudsman Scheme (ISO Scheme) which is intended to provide an independent dispute resolution service for noncommercial insureds. The first Ombudsman for the ISO Scheme took office in January 1995.

\section{THE DEVELOPMENT OF THE ISO SCHEME}

\section{A Origins of the ISO Scheme}

The development of consumer protection that has taken place over the last ten years has placed pressure on many enterprises and industries to look closely at their customer relations activities. In the case of the insurance industry, one of the long-standing areas of concern to consumer advocates was the lack of adequate means of redress for consumers in dispute with an insurer. ${ }^{1}$

1992 was something of a threshold year in regard to developments affecting insurance consumer redress. It was the year that the Banking Ombudsman took office. During the year the Ministry of Consumer Affairs conducted a survey of consumer awareness which included a question on insurance complaints. The Consumer Guarantees Bill was introduced. The Government released its Task Force Report on Private Provision for Retirement containing a recommendation that a savings ombudsman be established. ${ }^{2}$

* Barrister and Solicitor of the High Court of New Zealand.

1 See Consumers Institute "Insurance against the Insurers" (1992) 309 Consumer 3.

2 The Todd report. This was followed by the Retirement Income Act 1993, which established the Office of Retirement Commissioner whose functions include the monitoring of the effectiveness of persons appointed to consider complaints about savings and investments (s 6(e)). The multi-party Accord on Retirement Income, which forms the First Schedule to the Act, takes the matter further by stating a preference for there being a single Savings Ombudsman and requiring the Retirement Commissioner to review the Banking Ombudsman and the 
These developments, together with changes in company legislation and proposals for fundamental changes to the regulation of the general insurance industry in the form of the introduction of a statutory ratings system, ${ }^{3}$ provided the impetus for the insurance industry to make rapid movement to address its provision for dispute resolution. Up to this point the insurance industry had relied on a combination of company-based complaints handling with the industry organisations providing a general enquiries and referral service. Complaints resolution beyond this was effected through either arbitration, the Disputes Tribunal, or the courts.

Initially, the two main industry bodies, the Insurance Council and the Life Office Association, developed ombudsman proposals independently. With the release in June 1993 by the Ministry of Consumer Affairs of its report on insurance practices, ${ }^{4}$ the insurance industry was put under some pressure to develop a single ombudsman scheme. ${ }^{5}$ After lengthy negotiations, both within the industry and with government and consumer representatives, the ISO Scheme was finalised. The final stage was to seek the necessary approval from the Chief Ombudsman for the ISO Scheme to use the term "ombudsman". 6

\section{B The Structure of the ISO Scheme}

The foundation of the ISO Scheme is the document known as the "Rules of the Insurance and Savings Ombudsman Commission" (the Rules) which established two bodies: the ISO Commission (the Commission) ${ }^{7}$ and the industry Board (the Board). ${ }^{8}$ Both bodies are unincorporated, and have very small and specific memberships, and narrowly defined objects and functions.

ISO and report on the need for a statutory Savings Ombudsman. An initial review of the ISO is underway at present.

3 Now in place as the Insurance Companies (Ratings and Inspections) Act 1994.

4 Ministry of Consumer Affairs Study of Insurance Practices (Wellington, 1993).

5 Reports on consumer issues to the Board of the Insurance Council during this period identify the Minister of Consumer Affairs and the Chief Ombudsman as having firm views on this matter.

6 The Ombudsmen Act 1975, s 28A.

$7 \quad$ Rule 2.

$8 \quad$ Rule 23. 
The Board has eight members, two from each of the industry organisations involved. ${ }^{9}$ The object of the Board is to perform a narrow mixture of functions, these being:

(a) one-off functions: to appoint the first Chairperson and the first Auditor of the Commission; to establish regulations (Terms of Reference) for the ISO; and in the third year of operation to review the levies by which the Commission, is funded;

(b) occasional functions: to approve other industry groups or organisations; amendment of the Terms of Reference; to appoint two members of the Commission; to consult with the Commission as to the remuneration of its members; and to appoint the Chairperson and two representatives to the Review Committee of the Commission.

The Board meets infrequently and plays no direct part in the operation of the Commission or the office of the ISO. ${ }^{10}$

The Commission consists of two consumer representatives appointed by the Ministry of Consumer Affairs, an independent chairperson, and two Participant representatives appointed by the Board. ${ }^{11}$ The Commission sets and collects levies from the industry and determines the general priorities for the expenditure of these levies for the funding of the ISO Scheme. ${ }^{12}$

These levies enable the services of the ISO Scheme to be provided free to consumers. The Commission employs staff to carry out its objects, the principal employee being the ISO, who holds office for a renewable two year term. Though the Rules do not expressly state it, it is presumed that the primary object is to provide a complaints resolution service for noncommercial insureds, and that the means for achieving this are the establishment of the office of the ISO. ${ }^{13}$

The Commission has the duty to monitor the operation of the Rules and Terms of Reference and to make recommendations to the Board on issues arising. The Commission has the power to enter into contracts, make investments ${ }^{14}$ and to suspend or remove the ISO at any time in its absolute discretion. ${ }^{15}$

9 The Insurance Council, the Life Office Association, the Health Insurance Association and non-bank savings organisations. See Rule 23.2.

10 Rule 23.1.

11 Rule 8.

12 Rule 10.

13 Rule 16.

14 Rule 3.2.

15 Rule 3.3. 
The Commission must conduct periodic public reviews of the operation of the ISO Scheme and the Terms of Reference. ${ }^{16}$ The initial review is to be conducted at a time and in a manner that ensures that the report is available to the Retirement Commissioner for consideration in his initial report. ${ }^{17}$

The review committee is to consist of representatives of Participants, consumers and the Minister of Consumer Affairs and expressly excludes involvement by any member or employee of the Commission. The review committee has only recommendatory power, but it is required to consult widely and its reports are to be made public. Recommendations may be made on improvements to the ISO Scheme in such areas as publicity, access, procedures and the Terms of Reference.

To take part in the ISO Scheme an insurance company must first meet the criteria for an "Eligible Body". ${ }^{18}$ That is to say, they must be in the business of providing all or any of the insurance services specified in the Rules, and must be a member of the appropriate industry organisation. ${ }^{19}$ They must execute what is called the "Register" and pay any entry fee, to become a "Participant" in the Scheme. In other words the insurance company signs a contract with the Commission which binds them to pay the levies, publicise the Scheme, set up their own internal complaints procedures ${ }^{20}$ and comply with any Awards made by the ISO.$^{21}$

In return for the consideration given by Participants, they get the prestige of being associated with an ombudsman service and perhaps benefit from a cheaper, quicker and more private dispute resolution system. Participation may be terminated by the Commission if the Participant ceases to be eligible or breaches the terms of the contract. The Participant can resign from the Scheme by giving twelve months' notice. Given that some of the industry organisations involved have made participation in the ISO Scheme mandatory for the members of their organisation, ${ }^{22}$ termination or resignation from the Scheme may have wide consequences for the insurance company concerned.

16 Rule 22.

17 As required by the Retirement Income Act 1993, s 22.

18 Rule 9.

19 The Insurance Council, the Life Office Association, the Health Insurance Association and non-bank savings organisations. Refer Rule 23.2.

20 Rule 7.

21 Rule 16.3.

22 Life Office Association 1994 Annual Review (Wellington, 1995) 6; Insurance Council Fair Insurance Code (Wellington, 1994). It is understood that more than 60 insurers have become Participants, with perhaps 10 or so companies not yet involved, one of these being NZI General which has set up its own independent arbitrator scheme. It should be noted that the ISO Scheme does not apply to brokers at this stage. 
The role and status of the complainant, the consumer with a problem, is largely determined by the Terms of Reference.

\section{The Terms of Reference of the ISO Scheme}

The powers and duties of the ISO are constituted and governed by the Terms of Reference document. ${ }^{23}$ The scheme of these Terms of Reference is as follows: ${ }^{24}$

- Definitions

- Powers and Duties of ISO

- Limitations on powers of ISO

- Procedure for complaints

- Outcomes paragraph 1

paragraphs $2 \& 7$

paragraph 3

paragraphs $4,6, \& 8$

paragraph 5 .

The definitions in the Terms of Reference are the same as used in the Rules, with the specific addition of paragraphs 1.2 (a), (b), and (c). It is important to note that a Participant cannot be a Complainant and a complaint may only be made about those Services described in paragraph 1 . The resolution of a complaint may mean either withdrawal, dismissal, settlement, compromise, acceptance or determination of that complaint. Any reference to provision of services includes references to their non-provision.

The powers and duties of the $\mathrm{ISO}^{25}$ can be summarised as being:

- to operate a free and confidential complaints resolution service;

- to report on its activities to the Commission and to the public;

- to make recommendations on its Terms of Reference, relevant statutes and Codes of Practice; ${ }^{26}$ and

- to report breaches of Codes of Practice to the Commission.

23 Rule 16.2 .

24 The document uses the term "paragraph" to refer to its sections. The term is used the same way in this paper when referring to the Terms of Reference document.

25 Terms of Reference, paragraphs 2 and 7.

26 That is, the Insurance Council's Fair Insurance Code, the Life Office Association's Code of Business Practice, and Health Insurance Association's Code of Practice. See D Clarke's article on these codes of practice in this publication. 
The limitations prescribed in paragraph 3 actually serve to define the prerequisites for a complaint to be considered:

- The complainant must be the holder of a policy for personal or domestic insurance in New Zealand.

- The insurer complained of must be a participant in the ISO Scheme.

- The complainant must first have taken the complaint to the insurer's internal complaints process without success.

- The act or omission complained of occurred within the time constraints of the provisions of paragraph 3.1(f).

- The complaint is made to the ISO within two months of the failure of the insurer's process.

- The amount claimed is not more than $\$ 100,000$, although this can be increased with the consent of the insurer.

- The complaint must not relate to:

- - an insurer's assessment of risk;

- - the setting of premiums;

- - investment strategies, practices or policies;

- - the acceptance, renewal or cancellation of a policy; or

- - the imposition of conditions or exclusions on the policy's cover.

\section{The Process of Resolving a Dispute}

The ISO's approach to complaints is to be inquisitorial rather than adversarial, although discretion may be exercised as to procedure. ${ }^{27}$ A precondition for the use of the procedure is the written acceptance by the complainant of the provisions of paragraphs 8.1 and 8.2 of the Terms of Reference, which mandate a confidential "without prejudice" process and a return of documents requirement.

The ISO was not, under its original terms of reference, bound by any legal rule of evidence, by any rule or requirement of natural justice or procedural fairness. ${ }^{28}$ This position was modified in April 1996 when these exclusions were deleted from the Terms of Reference.

27 Terms of Reference, paragraph 4.1.

28 Terms of Reference, paragraph 4.5. 
The ISO is not bound by any previous decision of the office of the ISO. ${ }^{29}$ However, the ISO, in making any recommendation, is required to have reference to what is in his or her opinion, fair and reasonable in all the circumstances. ${ }^{30}$ The elements that the ISO may take into account in this context are very broad. ${ }^{31}$

The procedure by which a complaint is handled has five possible stages:

1 Has the complaint been taken through the insurer's internal complaints handling procedure? If not, then the complainant is referred back to their insurer. If it has, then the ISO may consider the complaint.

2 Is the complaint within the ISO's jurisdiction? The ISO will rule on this, but the ruling may be challenged in the High Court by the insurer. ${ }^{32}$ If the complaint is ruled to be out of jurisdiction, then the complainant will have to seek remedy elsewhere. If it is within jurisdiction, then the ISO will investigate the complaint.

3 Investigation may take any form deemed appropriate by the ISO, but will generally involve collection of information from both parties and some attempt to mediate between them with a view to reaching an agreement. If this is unsuccessful, either party can request the ISO to make a recommendation..$^{33}$

4 If a recommendation is requested, the ISO must give notice of one month to the parties of his intention to issue a recommendation. Once the recommendation is issued, the parties have one month in which to accept or reject it. If the complainant rejects the recommendation, then the ISO holds the papers for a further two months, returns the papers to the parties and the matter is at an end.

5 If the complainant accepts the recommendation, but the insurer rejects it, then the ISO makes an Award which becomes binding on both parties once the complainant formally accepts it. ${ }^{34}$ Such an Award can be enforced in the courts by the complainant against the insurer, if necessary. However, the insurer is strictly bound by the Rules of the Scheme to comply with Awards of the ISO, so it is should be unlikely that the complainant would need to take legal action.

29 Terms of Reference, paragraph 5.7.

30 Terms of Reference, paragraph 5.6.

31 Terms of Reference, paragraph 5.7 (a) - (f).

32 Terms of Reference, paragraph 4.1.

33 Terms of Reference, paragraph 5.2.

34 Terms of Reference, paragraph 5.4. 
In addition to this procedure, a "test case" option can be exercised by a Participant at any time before an Award is made. ${ }^{35}$ If the Participant states to the ISO that in its opinion the complaint involves or may involve either an issue which may have important consequences for the business of the Participant, or of Participants generally, or an important or novel point of law, and the Participant is prepared to give an undertaking to meet the reasonable and actual costs of the complainant in any court proceedings initiated within three months by either party, then the ISO will cease to consider the complaint.

Although the remedy in any given case is subject to the $\$ 100,000$ limit, incidental expenses incurred by the complainant in making and pursuing the claim are reimburseable in addition. It should be noted that an Award can be compensatory for direct loss or damage suffered by the complainant by reason of the acts or omissions of the Participant. ${ }^{36}$ The enforcement of remedies is not dealt with at all by the Terms of Reference.

The provisions of paragraph 5.9 of the Terms of Reference, in denying that any decision, determination, recommendation or Award shall be capable of any form of review, are clearly privative in intent. However, paragraph 8.2 of the Terms of Reference acknowledges the possibility of actions arising against the ISO and seeks to minimise the exposure of the ISO Scheme.

\section{E Reviewability of the ISO Scheme}

The relationship between the ISO and the courts is a problematic issue. On the one hand, the ISO's Terms of Reference expressly exclude appeal and review by any external body, but on the other hand they allow for the insurer's right to seek a declaration from the High Court on a jurisdiction decision made by the ISO. Clearly the intent is to provide some sense of certainty for the complainant once jurisdiction over the complaint is established. However, the question of whether an award made by the ISO can be reviewed remains uncertain given the ambivalence of the Terms of Reference toward the role of the courts.

The decision in Aegon Life ${ }^{37}$ has significance for the ISO Scheme in that it gives support to the provision in paragraph 5.9 of the Terms of Reference excluding judicial review of any decision of the ISO. As a binding term of contract between the insurer and the ISO Scheme, paragraph 5.9 goes further than the contract that applies to members of the UK Insurance Ombudsman Bureau (IOB).

The Articles of Association of the IOB contain only one reference to disputes between members and the scheme, and that is in Article 82 which requires the parties to go to

35 Terms of Reference, paragraph 6.

36 Terms of Reference, paragraph 5.4(b).

37 R $v$ Insurance Ombudsman, ex parte Aegon Life Assurance Ltd [1995] LRLR 101. 
arbitration when any difference arises as to the construction of the Articles, or for any other matter arising out of the relationship created by the Articles.

The combined effect of Article 82 and the fact that members of the IOB are contractually bound to abide by the decisions of the Ombudsman did not prevent an application for review being heard in the Aegon Life case. Given this, the possibility must exist for a member of the ISO Scheme to seek to use this avenue to overcome an unfavourable decision.

That the New Zealand courts will entertain applications from members of non-statutory bodies has been well evidenced by the cases. ${ }^{38}$ However, the current judicial position in New Zealand, as expressed by Fisher J in Peters $v$ Collinge ${ }^{39}$ sees a private body as being subject to non-contractual judicial review only in some special situations. Such situations include the exercise of quasi-public functions, ${ }^{40}$ or contemplation of an action of significant direct impact upon the public. ${ }^{41}$

The quasi-public function argument was unsuccessful in Aegon Life and in the writer's opinion would fail in the context of an application for review of the ISO Scheme for much the same reasons. The ISO Scheme is not performing a function that Government was otherwise going to undertake.

The consumer protection and advice services provided by the Government predated the ISO Scheme and continue to operate alongside the Scheme. The ISO Scheme does not have a comprehensive regulatory role: it regulates only the complaints handling of those insurers who choose to participate. Nor does the ISO Scheme have any disciplinary component and its decisions are not supported by any public law sanction.

The one aspect of the ISO Scheme that may provide a basis for distinguishing it from the IOB in relation to an application for review is that the ISO Scheme can only legally use the name "ombudsman" with the written approval of the Chief Ombudsman. ${ }^{42}$ This has the effect of making the ISO Scheme a licencee, that is the holder of a power to do something that they could not do without due authorisation.

Normally the holder of a licence could not be said to be susceptible to judicial review merely by virtue of its status as a licensee. However, it may be possible to construct an argument in relation to holders of a licence to use the name "ombudsman" that they are acting

38 See in particular, Finnigan $v$ New Zealand Rugby Football Union Inc [1985] 2 NZLR 159; Peters $v$ Collinge [1993] 2 NZLR 554.

39 [1993] 2 NZLR 554, 566.

40 See for example $R v$ Panel on Take-overs and Mergers, ex parte Datafin Plc [1987] QB 815.

41 Finnigan $v$ New Zealand Rugby Football Union Inc [1985] 2 NZLR 159.

42 Above $n 6$. 
in the same kind of public capacity as the Chief Ombudsman. If such an argument held up, then it may be possible to succeed in an application for review of a private ombudsman, given that there is the precedent of the Chief Ombudsman being the subject of review, ${ }^{43}$ and despite the privative intent of s25 of the Ombudsmen Act 1975.

\section{HOW DOES THE ISO SCHEME MEASURE UP?}

For dispute resolution processes to be regarded as having legitimacy, they must meet certain criteria. For the purposes of this article, the criteria by which the legitimacy of the ISO Scheme will be judged are those stipulated by the Chief Ombudsman ${ }^{44}$ and the Ministry of Consumer Affairs. ${ }^{45}$

\section{A ISO Scheme and the Chief Ombudsman's Criteria}

\section{Independence}

The ISO Scheme has been promoted as a totally independent complaints handling process and certainly independence is a highly valued quality in all forms of dispute resolution processes. Yet there is a question as to whether the ISO Scheme can be said to be truly independent.

From the examination of the Rules and Terms of Reference earlier in this article, it can be seen that the industry organisations exert a considerable influence over the Scheme as a whole, though not necessarily over the office of the ISO. The complete dependence of the Scheme on voluntary funding by levies must exercise a certain pressure on the operation.

There may be a natural reluctance on the part of the ISO to be seen to criticise the industry by, for example, making recommendations on the industry's codes of practice. Equally, the ISO may be reluctant to assert too much independence by seeking to amend the Terms of Reference. In either case the ISO may perceive a risk that industry support for the scheme may fall, both in active participation terms and in funding. Given the voluntary nature of the scheme, this risk is all too real.

There is also the risk that the industry organisations may feel that the ISO Scheme is competing with them if it takes on a role broader than merely resolving complaints. The requirement that the ISO make recommendations to the Commission rather than making submissions directly to either the industry bodies on codes of practice matters, or to select committees on legislation, restricts on the freedom of the ISO. Such a restriction is an

Commissioner of Police $v$ Ombudsman [1988] 1 NZLR 385 (CA).

44 See Report of the Ombudsman for the year ended 30 June 1992.

45 Above n 4, 42. 
effective way of stifling competition and maintaining control in the hands of the industry organisations.

In the foregoing discussion, independence has been viewed from a non-insurer perspective, but the independence of the Scheme must also be an issue for the members of the industry. They will wish to be assured that the office of the ISO is not drawn into acting as a consumer advocate. This is likely to bring close observation by insurers of the distribution of outcomes from the complaints received by the ISO. It is expected that the ratio of findings in favour of insurers to findings in favour of complainants will be watched particularly closely.

The comments of a former IOB Ombudsman, Dr Julian Farrand, to a parliamentary select committee in 1994 illustrates this issue. Dr Farrand had been asked by a member of the select committee why he was seen as being too independent, and therefore unpopular with the industry: ${ }^{46}$

I am supposed to be independent. People are quite happy with independent arbitrators or adjudicators as long as they are not impartial. I am impartial and I do not favour the industry. I also do not favour the consumer. I actually try to decide each case ... on the merits of that individual case. I do get a postbag from consumers who complain that I am the industry's lapdog, ... [and] I have the industry complaining that I am the consumer's champion when decisions go the other way.

This suspicion about outcomes makes the role of the ISO a particularly critical one. Not only is the office of the ISO expected to provide an independent service, but he or she must be seen to do so in a way that overcomes any perception of partiality. The personality and individual style of the person in such a role can influence the way in which the Scheme is perceived, as observed above in relation to the former IOB Ombudsman. The independence of the first ISO Commission Chairperson is a vital factor in this matter of perceptions given the key role to be played by the Commission.

\section{Charter}

As discussed above, the ISO Scheme is based on the Rules and the Terms of Reference, and these documents must therefore be regarded as the charter of the ISO Scheme. They are clearly the product of extensive multi-party negotiation and are not "user-friendly". The office of the ISO has produced a "plain language" version of the Terms of Reference which reduces the twenty-two pages of the original to nine easily-read pages in brochure format.

46 The Insurance Ombudsman Annual Report and Case Review 1994 (London, 1995) 55. Dr Farrand was giving evidence to the Treasury and Civil Service Committee on 13 April 1994, on the matter of financial services regulation with particular focus on the proposed Personal Investment Association Ombudsman. 
In addition, the ISO has developed a short introductory brochure in English and Maori, of which some 350,000 copies have been distributed.

The ISO has the right to make recommendations to the Commission on the Terms of Reference and on any legislation or codes of practice affecting the operation of the ISO. It would seem therefore that the charter criterion is met by the ISO Scheme. However, there are potential difficulties for the ISO in this matter which relate to the issues of the independence of the ISO from the industry (as discussed above), and a broader role for the ISO.

The writer would argue that although the basic charter requirements are met, a key question still remains unanswered. Should the role of the ISO be limited to that of a mere grievance procedure, or should it have a broader role, such as education, standards-setting, or even, as Birds said, $\mathbf{4 7}$ "to keep the conscience" of the industry? In the writer's opinion, the ISO Scheme is well placed to offer the industry and consumers much more than mere grievance handling.

\section{Direct receipt of claims}

Although the complainant must exhaust the insurer's internal complaints procedure before the ISO can deal with the case, it is still the complainant who brings the complaint to the ISO. Therefore this criterion appears to be met. However, as was commented by the National Consumer Council in the $\mathrm{UK}^{48}$ the internal procedures of insurance companies can become a treadmill on which complainants can be worn out, exhausting themselves rather than the procedure. Who decides when deadlock has been reached? The fact that the ISO Scheme does place a maximum time limit on this stage of the process is one of the definite strong points of the scheme.

This issue is common in disputes generally and is difficult to resolve since it makes sense to try to get the parties to resolve their differences directly if possible. However, it has to be recognised that there are imbalances in some relationships and that the personal insurance context is such a case. So it is important to the credibility of any complaints resolution scheme that the decision as to when to seek outside assistance in the dispute should be in the hands of the weaker party. In the present context, that means that the complainant should decide whether a complaint is referred to the ISO.

The writer believes that paragraph 3.1(d) of the ISO's Terms of Reference should be amended to make this right explicit for the complainant. Where there is an internal complaints procedure operated in a bona fide manner, the present right only applies either

47 J Birds and C Graham "Complaints against Insurance Companies" [1993] Consum LJ 113. Birds is quoting the IOB Ombudsman from 1989.

48 National Consumer Council Ombudsman Services (London, 1993) 9. 
when the insurer advises the complainant that deadlock has been reached, or three months after the complaint was formally made to the insurer, whichever comes first. Where there is no effective internal procedure, it is open to the complainant to take their complaint directly to the ISO, but it would be reasonable to assume that even in this case the complainant must have given the insurer an opportunity to respond to the complaint.

It is interesting to note that the ISO has drafted a model complaints procedure for Participants and is likely to assess any company procedure differing from this model when a complaint is brought directly to the ISO office. This is a useful approach, but requires a more substantive basis if the standard of internal complaints resolution is to improve.

At the minimum, it is suggested that the three months provision of paragraph 3.1(d) be amended to one month, and that the model complaints procedure be incorporated into the Terms of Reference so as to form a minimum standard.

\section{Free of charge}

There are no charges associated with the ISO's procedure for handling complaints. It could be argued that the complainants, as policyholders, are paying for the service through their premiums, but then so do the taxpayers pay for the "free" statutory ombudsman through their taxes. This issue could be researched by the Ministry of Consumer Affairs, or form an element in the ISO Commission's review committee deliberations, though it is difficult to see any effective way to inhibit insurers from passing on the cost of the ISO Scheme to policyholders.

The important point here is that cost should not be allowed to dissuade complainants from seeking redress. Though this Scheme provides its services free to complainants, the process of pursuing a complaint is not likely to be cost-free. There can be costs associated with preparing a claim, getting information to the ISO and perhaps seeking other advice when a settlement is proposed. The ISO does have the power to grant additional amounts to complainants to cover such incidental expenses, but from the wording of paragraph 5.4 of the Terms of Reference this appears to be limited to the cases in which an Award is made. It remains to be seen whether the ISO would see his discretion as extending to such expenses in the less formal settlements. This may need to be clarified in a future review of the Terms of Reference.

\section{Investigation, decision and remedy}

To satisfy these criteria the ISO must be empowered to investigate impartially the facts, reach an independent conclusion, and achieve a remedy where appropriate. ${ }^{49}$ The Terms of

49 S Richards "The Role of the Ombudsman" (Address given to the Insurance Institute of New Zealand National Seminar, 2 June 1994) 3. 
Reference explicitly provide for all three of these criteria as previously described. The degree of impartiality, independence and appropriateness achieved will need to be assessed in the fullness of time both through the publication of the work of the Scheme and by the regular review process which is mandated for the Scheme by the Commission's Rules.

\section{National coverage}

The ISO Scheme is a national service, though it has only one office, located in Wellington, thus potentially limiting access. However, such limitations can be overcome by the use of 0800 phone services and travel by the ISO to interview parties. The criterion only states that the scheme has to be "national in character" and although the ISO Scheme meets that requirement, it is the opinion of the writer that this criterion is too narrow to meet the standard expected of a good dispute resolution process.

\section{Public Accountability}

The ISO is required by the Terms of Reference to publish an annual report so as to inform the community of the ISO's activities. The annual reports published by the various Banking Ombudsmen and by the IOB set a very high standard which, with respect, has yet to be matched by the Chief Ombudsman's annual report to Parliament and periodic compendia of cases. It is certain that a high quality report can be very useful means of publicising the scheme and for encouraging public discussion and research about the scheme and the issues that come to its attention. Access to such reports is of critical importance if they are to be of value to the community.

The Rules of the ISO Scheme require public reviews to be held periodically, as discussed previously. The degree of actual consultation undertaken by the review committee will determine the validity of this approach. For example, issues such as customer satisfaction with the scheme will require surveys of complainants to be done. This could be problematic in view of the confidentiality requirements of the scheme, not to mention the restrictions imposed by the Privacy Act. The Terms of Reference may need amendment to allow for such survey work to be undertaken, or to require a complainant satisfaction report to be obtained in each case handled by the ISO.

Such public review processes are only meaningful if their recommendations have some effect on the body reviewed. As has been observed in Australia, simply producing a large number of recommendations does not necessarily guarantee change. Unless there is some prior commitment to adopt, or at least negotiate the adoption of, the recommendations of a review then the exercise is reduced to being mere commentary.

The accountability of the Chief Ombudsman to Parliament makes certain that the public interest is taken into account. This cannot be said of the private ombudsmen. 


\section{Adequacy of the criteria}

The question of whether the existing criteria for approval of the use of the term "ombudsman" are adequate to the situation of multiple non-statutory ombudsman schemes has to be asked. If private sector ombudsmen are to be a long-term feature of New Zealand's dispute resolution environment, then it is suggested that the criteria used by the Chief Parliamentary Ombudsman should be reviewed with a view to imposing some clarity as to the place of legal rules, natural justice and independent review in such processes.

It is suggested that there could be an amendment made to the Ombudsmen Act 1975, to clarify the power of the Chief Ombudsman as regards sanctions against private ombudsmen. As the Act stands, the Chief Ombudsman can give approval, and a penalty can be imposed on anyone using the name without approval. However, the Act is silent as to the ability of the Chief Ombudsman to withdraw approval once given, and the criteria used for approval are not a part of the statute. The criteria themselves are minimal and contain no indication of standards by which the performance of a private ombudsman may be measured.

\section{B The ISO Scheme and the Ministry of Consumer Affairs Criteria}

There are some elements in the Ministry's criteria which require comment with regard to the ISO Scheme.

\section{Timeliness}

The Ministry believes that any complaint should be dealt with reasonably speedily and that there should be indicative guidelines as to timeframes for resolution of the dispute. The ISO Scheme does not yet have such guidelines, which is perhaps understandable given the short time that the Scheme has been in operation.

Despite this reasonable performance to date, it is the writer's opinion that the ISO Scheme is deficient in not stipulating at least some broad guidelines for timing the various stages in the process. Without such guidelines, the complainant has no measure by which to assess whether the process is proceeding reasonably. If the ISO Scheme is to be seen as a better option than the courts, then it needs to give some assurance of certainty, if not of outcome, then at least of procedure.

\section{Sanctions}

The Ministry states that there should be effective sanctions to dissuade insurers from rejecting decisions. The only present sanction, other than litigation in contract, is in the power of the Commission to terminate the participation of an insurer in the Scheme.

Such an action would have a potentially serious effect on a provider of life insurance. It would amount to a breach of the LOA Code of Business Practice, putting at risk the insurer's "authorised" status under s 7A(2) of the Securities Act 1978, and thus jeopardising 
the insurer's exemption from the general obligations imposed on issuers of securities to the public.

The effect of termination of participation in the Scheme on other kinds of insurer is less clear, but is likely to be of lower impact. Since there are a small number of general insurers (most notably NZI Insurance) who are not participants in the ISO Scheme and who still function without difficulty, being excluded from the Scheme does not appear to have any sanction value. The Ministry, in proposing that effective sanctions should exist to dissuade insurers from rejecting decisions, did not identify what such sanctions might be. It seems likely that the Ministry's focus was on there being a system in which binding decisions would be made, and that the enforceability of such decisions would provide the requisite sanctions.

Given the importance of public relations to the insurance industry, it is often suggested that the negative publicity of an insurer being seen to renege on its commitment to the ISO Scheme would be a sufficient deterrent, obviating the need for explicit sanctions. Whether such a view is credible will only be known once the data is available to be assessed.

\section{Consumer involvement}

The Ministry puts great emphasis on consumer involvement in the oversight of dispute resolution schemes. The Commission would seem to meet the Ministry's minimum requirement for consumer representation in that the Commission does consist of equal numbers of industry and consumer representatives. However, the fact that the Board has no consumer representation on it and that the Board has power of appointment over a number of positions, means that out of the nineteen positions in the Board, the Commission and the Review Committee, the Board is in control of fourteen. Even allowing for the undoubted independence of the current Chairperson of the Commission, there is clearly not a state of equality between industry and consumer representation within the ISO Scheme.

\section{Publicity}

The publicity requirements seen as necessary by the Ministry are generally being met by the ISO. There is clearly a need for a monitoring programme to be set in place, examining such matters as whether insurers are receiving and utilising ISO Scheme information, and on what occasions do they make the insured aware of the ISO Scheme. Insurers have a contractual duty as participants in the ISO Scheme to inform their customers about internal complaints procedures and the ISO Scheme. This duty can be met to some degree by including appropriate explanatory information on proposal and policy documents.

\section{Fairness and other matters}

The fact that the ISO has to have regard to what is fair and reasonable in making decisions does not deal with the question of procedural fairness. In paragraph 4.1 of the 
Terms of Reference the ISO is given the power to decide on the appropriate procedure in respect of each complaint and decisions on such matters are expressly barred from appeal or review in paragraph 5.9 .

The main requirements of natural justice in this context are:

(a) that adequate notice of the reasons for both the insurer's decision and the consequent decision made by the ISO be given to the complainant;

(b) that both complainant and the insurer are given reasonable opportunity to be heard by the ISO; and

(c) that the decisions of the ISO are made without bias.

The Terms of Reference contain no guarantees on any of these aspects.

A further factor which serves to complicate the proper functioning of natural justice is the investigative mode of dispute resolution used by the ISO. While this approach may be appropriate for disputes involving parties of significantly unequal power, or where there are sensitive issues (as in sexual harassment cases), it does bring with it certain problems. In 1992, the IOB Ombudsman was explicit about the problems inherent in the multifunctional nature of the investigative approach typically adopted by ombudsmen: 50

[F]or those concerned this may involve problems: statements may be made and facts conceded to a conciliator which would not be admitted to an adjudicator. The inquisitorial approach adopted by Ombudsmen leaves little room for "without prejudice" communications. Equally the ombudsman must himself bear firmly in mind the capacity in which he or his staff is communicating with the parties at any stage of the proceedings so as to avoid any suggestion of premature prejudice... . In practice this can prove difficult.

The amendments made in April 1996 seek to align the Terms of Reference with the procedural standards used by the Chief Ombudsman, in particular the provisions of s 18(3) of the Ombudsmen Act 1975, which allow the Ombudsman to hold hearings if deemed necessary.

\section{CAN COMPLAINTS HANDLING BE RATED?}

With the advent of the new ratings regime for general insurers, ${ }^{51}$ it may be opportune for the industry and the regulators to consider the possibility of adding a requirement to the ratings assessment process, dealing with the standard of complaints performance of insurers.

50 Above $n$ 48, 45.

51 Insurance Companies (Ratings and Inspections) Act 1994. 
This should not be seen as an unreasonable requirement by the industry since they have characterised the ratings regime as being more than a merely financial rating exercise. ${ }^{52}$ Performance in complaints matters would be a measure that consumers could use to assess the credibility of insurers and would add significantly to the weight and credibility of the ISO Scheme.

Such a measure may also effectively address the non-participation problems attendant on any totally voluntary scheme by creating an incentive for insurers to either join the ISO Scheme or come up with an alternative that is at least as good. This proposed measure could also provide the means to impose sanctions on insurers of the kind that are at present only applicable to life insurers, as noted above.

The data for such a rating exercise are already collected by the ISO and used in the calculation of funding levies. This data could be combined with regular statistical reports on the insurers' internal complaints systems to produce a complaints profile to add to the other measures used in the rating process.

The fact that the Insurance Council is designated as the body that negotiates with and recommends ratings agencies ${ }^{53}$ means that the industry itself is setting the standards for the ratings process and extending its self-regulation. Therefore, given that the ISO Scheme is also an industry self-regulation initiative it would be reasonable to expect the suggested integrated approach to be taken.

The new ratings system clearly has some public relations value to the industry and given that it is likely that the ratings system will replace the present statutory deposits system, $\mathbf{5 4}$ then it is not unreasonable for the public to expect that the ratings system will be meaningful to consumers in the fullest possible sense.

\section{CONCLUSION}

It is clear that there is some way to go yet in the development of satisfactory dispute resolution processes in the insurance and savings industry. New Zealand's recent initiative with the ISO Scheme appears to be a step in the right direction, charting a course between the excesses of formalism and informalism. There are clearly some grounds for concern about the ISO Scheme, though it is acknowledged that it is early days yet and much will depend on the ability of the first ISO to establish an effective and independent operation.

52 Discussion held with the Chief Executive of the Insurance Council, 19 April 1995.

53 Above n 51, s 17.

54 Insurance Companies Deposits Act 1955. All enterprises in the business of insurance are required to pay a deposit to the Public Trustee as a measure which was originally intended to provide a minimal level of security for insureds. The amounts required for deposit can range from as little as $\$ 2000$ to a maximum of $\$ 500,000$. 
There are questions to be resolved about accessiblity, the adequacy of public information, and the degree of actual independence achieved by the ISO Scheme. The question of the fairness of the ISO Scheme in light of the strictures written into the Terms of Reference, makes impartial and public review absolutely essential. Real effort will have to be made to avoid the Procrustean possibilities of these strictures.

The real benefit to the insurance and savings industry must surely come from encouraging use of the ISO Scheme by complainants and for this to happen the Scheme will have to establish a reputation for independence, flexibility and effectiveness. If this is achieved then the ISO Scheme can justly reject the labels that have been applied to its UK counterpart ("Industry lapdog" or "Consumer champion") and instead fulfill the role that the Insurance and Savings Ombudsman has identified, that of an independent agent for change. ${ }^{55}$

55 T Weir "Insurance Tomorrow" (Address given to the Insurance Institute of New Zealand National Conference, 31 May 1995) 16. 
